\title{
ED \\ National Strategy for Health Care System Preparedness
}

\author{
Ann Knebel, RN, DNSc, FAAN, and Sally Phillips, RN, PhD
}

$\mathrm{H}$ ealth care system preparedness is a complex area of study, but there is a growing body of knowledge about the topic. A PubMed search yielded 1300 articles, with more than 300 of them being published in the last 2 years. A full treatment of the topic is not possible within the confines of an editorial, so we focus on 3 elements that we believe are essential for creating a national strategy for health care system preparedness: systems thinking, infrastructure resiliency, and integrated planning.

When we say health care system preparedness, what do we mean? In the past, the focus of preparedness was the ability to surge to meet the increased demands associated with a catastrophic event. The definition of surge has expanded over time to include not only space, staff, and supplies but also the creation of systems and standard operating procedures that integrate science into preparedness activities. ${ }^{1}$ The definition of surge typically focuses on individual facilities, or perhaps a small network of facilities and alternate care sites. With a national strategy for health care system preparedness, we need to expand beyond a focus on surge capacity toward systems thinking. Systems thinking involves the following2:

Identifying the broad range of stakeholders and establishing networks among them

Managing and transferring information among the stakeholders

Analyzing system dynamics

Harnessing the problem-solving capabilities of multiple stakeholders

Managing the system through participative approaches

The list of stakeholders that comprise the health care preparedness system is broad and would include all health care entities including pharmacies, health centers, home care, rehabilitation centers, and public health, as well as key community response entities such as fire safety, law enforcement, and emergency management. ${ }^{3}$ In fact, the community itself must be part of the system, as was described by $\mathrm{Kapucu}^{4}$ in his study of the 2004 hurricane season in Florida. Although this makes logical sense, there are inherent difficulties with making this happen.

One difficulty is that among the diverse group of stakeholders there is not a readily identifiable coordination entity for managing and transferring information among the stakehold- ers. Another difficulty is the system dynamics of some stakeholders who are financial competitors. However, through systems thinking it is possible to harness the problem-solving capabilities of multiple stakeholders to create a functional system. The stakeholders need to identify a coordination entity that will be crucial for system operations. Managing and transferring information can be facilitated through information systems ${ }^{5}$ that share data such as inventories of resources to allow for greater collaboration and coordination. Competitors must determine how they will work together during times of need. Embedding preparedness into day-today initiatives that are focused on quality improvement and patient safety may serve as an incentive.

Progress already is being made in building systems for health care preparedness. A specific example is the work that has been done to create regional trauma systems. Effective trauma systems involve community hospitals, trauma centers, emergency medical services, communication networks, standardized protocols, relationships, and quality assurance. ${ }^{6}$ Hick and colleagues ${ }^{6}$ suggest that regionalization can be applied to the broader health care system to improve disaster health care response. We agree and would argue that these regionalized approaches need to be taken to the next level by creating a system of systems that link multiple regional networks.

The second element that is essential for creating a national strategy for health care system preparedness is the resiliency of the system. Resiliency in this context is defined as the capacity to maintain continuity of activities even in the face of threats, disaster, and adversity. ${ }^{7}$ Resiliency results when 4 factors are continuously achieved. The first factor is robustness, meaning that a society continues to function during a disaster. Second is resourcefulness, which means managing the response to a disaster as it unfolds. Third is rapid recovery, or the ability to return things to normal as quickly as possible after the disaster. Fourth is the ability to absorb new lessons drawn from the catastrophe. ${ }^{8}$

The damage to the health care infrastructure in the aftermath of Hurricane Katrina provided insights into the vulnerabilities of the health care infrastructure. Communications were disrupted; basements with generators and stored food and water were flooded; power, water, and sewage systems were 
inoperable for prolonged periods; and trash pickup stopped..$^{9}$ It is one thing to be prepared to respond with an intact infrastructure; it is another when the infrastructure is impaired. A national strategy for health care system preparedness needs to engage stakeholders in a planning process that considers the 4 factors that contribute to resiliency.

The third element of a national strategy for health care system preparedness is integrated planning. By integrated planning we mean that representatives from across the different tiers of response ${ }^{10}$ define how all of the tiers will work together to support the local response to a given scenario. The National Planning Scenarios developed by the White House Homeland Security Council are 1 set of scenarios that can be used. ${ }^{11}$ The scenarios used for integrated planning should be based on the specific hazards that the community is likely to face, because preparedness must start at the local level. Tools are available to assess hazards and vulnerabilities. One example is a tool published by Kaiser Permanente. ${ }^{12}$

Understanding the numbers and types of casualties that can be expected for each of the scenarios can promote integrated planning by allowing states and regions to realistically compare available assets to likely needs and thus determine the gaps to be filled by the other tiers of the system. The Office of the Assistant Secretary for Preparedness and Response (ASPR) and the Agency for Healthcare Research and Quality developed a set of models for estimating resource needs for various scenarios. ${ }^{13}$ These models draw upon knowledge of the identified threats and potential victim characteristics to help planners anticipate the public health and medical care requirements so that planning is aligned with the capabilities and capacities to respond.

ASPR serves as the lead for federal public health and medical support under the National Response Framework. ${ }^{14}$ States can promote integrated planning by engaging representatives from all tiers of response, including the federal tier. ASPR has regional emergency coordinators stationed across the United States to support integrated planning activities. ${ }^{15}$ In this way, all of the components of the system can understand how the response will be managed at the local level, what the likely gaps will be, and what assets may be needed to fill those gaps. Regional and federal assistance can be used more efficiently during response if there is a well-developed integrated plan that determines in advance what assets will be needed from outside sources.

To support integrated planning, ASPR develops "playbooks" for the national planning scenarios ${ }^{11}$ that are available on the ASPR Web site. ${ }^{16}$ The playbooks provide a concept of operations and action steps for the federal response to the different scenarios. The goal is to make these plans transparent to state and local entities and to promote integration across the tiers of the system. The playbooks are updated and revised based on lessons observed in exercises or events and input from state and local entities. This level of detailed planning during preparedness requires an investment of a significant amount of time and resources, an investment that will pay huge dividends during response.

States and localities often look for guidance and direction to develop integrated plans. The Agency for Healthcare Research and Quality and ASPR have worked together on other initiatives, such as a community planning guide on allocation of scarce resources ${ }^{17}$ and strategies for engaging home health care organizations in pandemic preparedness and response. ${ }^{18}$ The community planning guide on allocation of scarce resources discusses ethical and legal issues regarding allocation of scarce resources. It also discusses practical suggestions for planning with scarce resource situations in different care environments such as prehospital, hospital, and alternate care sites. The guide also includes a chapter on palliative care because scarce resource situations may dictate a requirement to ensure a dignified death. ${ }^{17}$ The home health guide looks specifically at how home health care can support surge capacity during a pandemic influenza event. ${ }^{18}$ These tools can assist state and local planners with evidence-based approaches to integrated planning.

Although there is a growing body of knowledge regarding health care system preparedness, we do not yet have a national system. A national strategy for health care system preparedness would build on the important work completed to date and create a system of systems that is resilient and integrates preparedness across all of the tiers of response. It is only through such an integrated system that we will achieve the vision of a nation prepared to respond to the public health and medical consequences of disasters.

\section{About the Authors}

Dr Knebel is Deputy Director for Preparedness Planning, Office of Preparedness and Emergency Operations, Office of the Assistant Secretary for Preparedness and Response, Department of Health and Human Services; Dr Phillips is Director of Public Health Emergency Preparedness Research, Center for Primary Care, Prevention, and Clinical Partnerships, Agency for Healthcare Research and Quality, Department of Health and Human Services.

Address correspondence and reprint requests to RADM Ann R. Knebel, RN, DNSc, 200 Independence Ave, SW, Room 638G, Washington, DC 20201 (e-mail: ann.knebel@hhs.gov).

\section{Authors' Disclosures}

The authors report no conflicts of interest.

ISSN: 1935-7893 (C) 2009 by the American Medical Association and Lippincott Williams \& Wilkins.

DOI: 10.1097/DMP.0b013e31819dbe36

\section{REFERENCES}

1. Hick JL, Hanfling D, Burstein JL, et al. Health care facility and community strategies for patient care surge capacity. Ann Emerg Med. 2004:44:253-261.

2. Leischow SJ, Best A, Trochim WM, et al. Systems thinking to improve the public's health. Am J Prev Med. 2008;35 (Suppl 2):S196-S203.

3. Braun BI, Darcy L, Divi C, et al. Hospital bioterrorism preparedness linkages with the community: improvements over time. Am J Infect Control. 2004;32:317-326. 
4. Kapucu N. Collaborative emergency management: better community organising, better public preparedness and response. Disasters. 2008;32: 239-262.

5. Braun BI, Wineman NV, Finn NL, et al. Integrating hospitals into community emergency preparedness planning. Ann Intern Med. 2006; 144:799-811.

6. Hick JL. Trauma systems and emergency preparedness: the hand bone's connected to the arm bone. Acad Emerg Med. 2005;12:875-878.

7. Carafano JJ. Resiliency and Public-Private Partnerships to Enhance Homeland Security. The Heritage Foundation Web site. June 2008. http://www.heritage.org/research/Homelanddefense/bg2150.cfm. Accessed December 6, 2008.

8. Flynn SE. America the Resilient. Defying Terrorism and Mitigating Natural Disasters. The Foreign Affairs Web site. March/April 2008. http://www.foreignaffairs.org/20080301 faessay87201/stephen-e-flynn/ america-the-resilient.html. Accessed December 6, 2008.

9. Rodriguez H, Aguirre BE. Hurricane Katrina and the healthcare infrastructure: a focus on disaster preparedness, response, and resiliency. Front Health Serv Manag. 2006;23:13-24.

10. Barbera JA, Macintyre AG. In: Medical Surge Capacity and Capability: A Management System for Integrating Medical and Health Resources During Large-Scale Emergencies. 2nd ed. Knebel A, Trabert E, eds. US Department of Health and Human Services Web site. http://www.hhs.gov/ disasters/discussion/planners/mscc/index.html. Accessed December 6, 2008.

11. National Planning Scenarios. Created for Use in National, Federal,
State, and Local Homeland Security Preparedness Activities. Homeland Security Council Web site. April 2005. http://cees.tamiu.edu/covertheborder/ TOOLS/NationalPlanningSen.pdf. Accessed December 6, 2008.

12. Medical Center Hazard and Vulnerability Analysis. Kaiser Permanente Web site. 2001. http://www.njha.com/ep/pdf/627200834041PM.pdf. Accessed December 6, 2008.

13. Hospital Surge Models. Agency for Healthcare Research and Quality Web site. http://www.hospitalsurgemodel.org. Accessed December 6, 2008.

14. National Response Framework. FEMA Web site. 2008. http://www. fema.gov/emergency/nrf. Accessed December 6, 2008.

15. Regional Emergency Coordinators. US Department of Health and Human Services Web site. http://www.hhs.gov/aspr/opeo/regions/index.html. Accessed December 6, 2008.

16. Office of the Assistant Secretary for Preparedness and Response Playbooks. US Department of Health and Human Services Web site. http:// www.hhs.gov/aspr. Accessed December 6, 2008.

17. Phillips SJ, Knebel A, eds. Providing Mass Medical Care With Scarce Resources: A Community Planning Guide. Agency for Healthcare Research and Quality Web site. February 2007. http://www.ahrq.gov/ research/mce. Accessed December 6, 2008.

18. Knebel A, Phillips SJ, eds. Home Health Care During an Influenza Pandemic: Issues and Resources. Agency for Healthcare Research and Quality Web site. July 2008. http://www.pandemicflu.gov/plan/healthcare/ homehealth.html. Accessed December 6, 2008. 